\title{
Were they joking? Depends on social dominance orientation
}

\author{
Aneika L. Simmons \\ Assistant Professor of Management \\ Department of Management and Marketing \\ Sam Houston State University \\ Huntsville, TX 77341-2056 \\ Rochelle Parks-Yancy \\ Associate Professor of Management \\ Department of Business Administration \\ Texas Southern University \\ Houston, TX 77004
}

\begin{abstract}
Author note
Correspondence concerning this article should be addressed to Dr. Aneika L. Simmons, Department of Management and Marketing, Sam Houston State University, Huntsville, TX 77341-2056. Email: aneika_simmons@shsu.edu.
\end{abstract}

\begin{abstract}
This investigation was conducted to determine how social dominance orientation (SDO) influences perceptions of race related comments. We discovered that individuals that were high in SDO perceive that a White authority figure was joking when a derogatory race related comment was made about White students, but they did not believe that a Black authority figure was joking when the same comment was made toward White students. This study further demonstrates that SDO plays a vital role in how individuals perceive interactions that involve race related bias.
\end{abstract}

Keywords: social dominance orientation, diversity, joking

\section{Introduction}

Jokes have long been used in a racial context. There are several purposes of such jokes, such as to demean particular racial groups, to develop camaraderie on the basis of race and to mock racial stereotypes (Hughes, 2003). Stories abound in the popular press about entertainment figures, politicians, and every day people making and/or reacting to comments that were perceived as racially motivated. Research has also found that people have various perceptions of comments that may be interpreted as racial jokes (Davies, 2010; Duncan, 1982; McClelland \& Auster, 1990). For example, on predominantly White college campuses, racial minority groups believe that some joking 
comments that are made by White students are actually racist and not, in fact, funny, though the White students are not necessarily intending to be offensive (McClelland \& Auster, 1990).

Nevertheless, people's perceptions of whether racial comments are acceptable jokes or offensive expressions depend on a variety of factors. One factor is the similarity of race between the target of the jokes and the person making the jokes. Studies have found that people are much more accepting of even blatantly racially offensive jokes when the target of the joke is the same race as the person making the joke (Davidson, 1987; Davies, 2010; Park, Gabbadon, \& Chernin, 2006). Individuals apparently believe that it is more acceptable to joke about "your own kind" even if the jokes are insulting, than if the person making the joke is a different race than the target of the joke. In the latter case, the person who made the joke risks being viewed as racist and some form of reprimand or social ostracism may follow.

However, there may be a more comprehensive explanation as to whether or not people perceive racial comments as acceptable remarks, offensive comments, or jokes. Perhaps beliefs and convictions about race and status may influence perceptions of racial comments and/or jokes; we look to Social Dominance Theory (SDT) to provide a rationalization for why this may be the case. SDT is based on the idea that individuals within society are generally structured in groups that are organized in a social hierarchy (Sidanius \& Pratto, 2003). According to SDT, the types of oppression observed among groups within society such as racism, sexism, classism, and ethnocentrism are all the result of the inclination for individuals to generate and sustain group based hierarchies within society (Sidanius, Pratto, van Laar, \& Levin, 2004).

Thus, the degree of belief that individuals have in the tenants of SDT may also affect their perceptions of racial comments. That is, if individuals seek to maintain existing social hierarchies, they may be inclined to feel outrage if a low status group member (e.g., Blacks) makes comments or jokes that are critical of high status group members. However, they may be inclined to support or overlook racial comments or jokes that are critical of low status group members, irrespective of the race (and, thus, status) of the person who made the comment or joke. Furthermore, individuals who are high in SDO may believe that high status group members (e.g., Whites) have the right to engage in activities that help maintain long established hierarchies within society (e.g., making comments that reflect racism), which is counter to current acceptable social behaviors. For the purposes of this investigation racism is defined as, "the definitive attribution of inferiority to a particular racial/ethnic group and the use of this principle to propagate and justify the unequal treatment of this group" (Essed 1990, p. 11).

To our knowledge, no previous work has sought to discover how SDO may influence perceptions of race related comments that may be identified as jokes. We believe that it is important to determine how they may interact considering the increasing level of diversity and communication (which provides more opportunities for different perceptions of race related comments) in the workplace. Thus, this study seeks to determine the role that SDO might have on the perceptions of racial comments about 
African Americans and Caucasians. We particularly address how SDO influences people's beliefs, in terms of the extent to which race related comments are perceived as jokes.

\section{Social Dominance Theory and Joking}

SDT is a theoretical framework, which helps to explain group based hierarchies that are observed around the world. For instance, men tend to have higher social value than women, Caucasians tend to have higher social value than African Americans, and upper class individuals tend to have higher social value than lower class individuals. The differences between these groups tend to lead to conflict since those with the higher social value are often inclined to want to sustain traditional hierarchies (which supports their high status) while those with the lower status make strides to obtain higher levels of social value (Sidanius \& Pratto, 1999). SDT explains that both individuals and institutions affect the maintenance of established societal hierarchies. For instance, individuals may help to maintain traditional hierarchies by making selection choices based on race, while financial organizations (an institution) may help maintain traditional hierarchies by more readily providing funds for high status group members (as compared to low status group members) (Morrison \& Ybarra, 2008; Sidanius, Pratto, van Laar, \& Levin, 2004; Umphress, Simmons, Boswell, \& Triana, 2008).

Individuals who are high in SDO are generally inclined to maintain these observed group based hierarchies. In fact, SDO is defined as, "...the degree to which one endorses group-based social inequality and group-based dominance" (Sidanius \& Veniegas, 2000, p. 12). Research has demonstrated that high SDO's, whether or not they are in a position of authority, may make strides to maintain the traditional hierarchy that have been historically observed in society. For instance, individuals who are high in SDO are more likely to make negative comments about lower status group members (Simmons \& Parks-Yancy, 2011). Although comments are a more indirect way of displaying bias as compared to denying a home loan for a low status group member, for example, it is still an effort to maintain or even enhance traditional hierarchies. We believe that perceived joking, a more specific type of communication, may also play a key role in terms of race related comments that could be used to maintain established hierarchies.

Joking is defined as, "any communication with a witty or funny intent known in advance by the teller" (Duncan, 1982, p. 136). Joking can be used as a way to share unpopular beliefs in a humorous manner. Historically, there is the perception that individuals are likely to be offended when Whites make jokes about Blacks, as Blacks are the historically disenfranchised group (Davidson, 1987). However, we assert that although Whites are typically held as the culprit for comments with inappropriate racial content, Blacks may also be identified as the source of inappropriate comments. This may especially be the case if an individual who is high in SDO hears race related remarks. High SDO's may interpret racial comments differently than individuals who are low in SDO as they are motivated to ensure that high status group members are viewed as 
superior and to ensure that low status group members are perceived as subordinate (Sidanius \& Pratto, 1999).

Based on SDT, individuals who are high in SDO may be comfortable when comments are made that help support traditional hierarchies (e.g., Whites superior to Blacks), but they may be distressed when derogatory comments are made about high status group members. Comments may elicit an even stronger negative response if a hierarchy attenuating remark is made by a Black authority figure. To be clear, hierarchy attenuating behaviors or comments are those in which subordinate groups (i.e., low status group members) are esteemed or shown value or when high status group members are devalued or criticized (Pratto, Stallworth, Sidanius, \& Siers, 1997; Sidanius \& Pratto, 1999). In addition, if a White authority figure makes a disapproving comment towards high status group members, it is likely to be dismissed or overlooked as high SDO's are inclined to yield to authority figures, particularly high status group members, and assert that they have a right to make such comments even if they do not agree with them (Sidanius \& Pratto, 1999; Umphress, Simmons, Boswell, \& Triana, 2008). Thus, individuals who are high in SDO are more likely to perceive a race related comment to be comical or a joke (and give the authority figure the benefit of the doubt) when a White authority figure makes a bias comment towards White students.

Research also suggests that high SDO's will not perceive it to be a joke when a Black authority figure makes a bias comment towards White students. Instead, they are likely to be offended as this would be a hierarchy attenuating behavior. In addition, individuals who are high in SDO may be inclined to perceive that a truth is being shared (as opposed to a joke) when a Black or White authority figure makes a derogatory or hierarchy enhancing remark towards Black students (i.e., low status group members). This is the case as hierarchy enhancing behaviors are observed when the rights and freedoms of high status group members are protected or when stigmas or negative social values are attributed to low status group members (Pratto, Stallworth, Sidanius, \& Siers, 1997). Based on this information, we investigate the following hypotheses:

Hypothesis 1: Individuals who are high in SDO are more likely to perceive joking when white students are the target of derogatory race related comments and a White professor is the source as compared to a Black professor.

Hypothesis 2: Individuals who are high in SDO are less likely to perceive joking when black students are the target of derogatory race related comments and a White professor is the source as compared to a Black professor.

\section{Quantitative Methods}

\section{$\underline{\text { Participants }}$}

We recruited 113 business students from a mid-sized university in the south. Men consisted of $46.9 \%$ of the participants, while $53.1 \%$ were women. The majority of the participants were White (61.9\%), 16.8\% were Black, $12.4 \%$ were Latino, 3.5\% were 
Asian, and 5.3\% indicated that were best identified with Other. The least amount of participants were Sophomores (4.4\%), 67.3\% were Juniors, and $27.4 \%$ were Seniors. $31 \%$ of the participants were not employed, $49.6 \%$ were part-time, and $19.5 \%$ were fulltime. $79.7 \%$ of the participants were between the ages of 19 and 23 .

\section{Procedure}

We used two different phases to collect the data for this investigation. In Phase One, we collected the independent variables: modern racism, race, racial identification, gender identification, and SDO. In Phase Two, the students were presented with a scenario that involved a professor and students in which a race related comment was made.

Phase One Independent Variable:

Social Dominance Orientation. SDO was measured using a 16 item scale developed by Sidanius, Pratto, Sinclair, and van Laar, 1996. A 7-point Likert scale was utilized and the measure was found to be reliable $(\alpha=.84)$. A sample reversed item includes, "All groups should be given an equal chance in life."

Control Variables:

Race. Race was captured during the first phase of the investigation. It was important to control for this information because Whites are often higher on SDO as compared to other races (Sidanius \& Pratto, 1999). The race of the participant was coded as $0=$ non-White and $1=$ White.

Racial identification. This item was measured using a four item scale developed by Davidson and Friedman (1998). This measure is critical, as individuals who more strongly identify with those of a similar race may have varied attitudes of others that are of a different race (Edmondson, Barnes, \& Gupte, 2008). The scale was found to be reliable $(\alpha=.79)$.

Modern Racism. This item was measured utilizing a seven item scale (McConahay, Hardee, \& Batts, 1981). Modern racist tend to have a negative disposition towards low status group members (e.g., Blacks) of society. This type of racism is often latent, and only displayed when racist behaviors can be justified. A sample reversed item was, "Discrimination against blacks is no longer a problem in the United States." The scale was found to be reliable $(\alpha=.84)$.

Gender Identification. This item was measured because some individuals are likely to be bias towards their gender depending on their level of gender identification. A sample item is, "I feel I can trust persons of my gender more than people of the other gender." The scale was found to be reliable $(\alpha=.71)$. 
Phase Two independent variable:

In Phase Two, we followed the methodology utilized by Cunningham, Ferreira, and Fink (2009). The individuals who participated in this study were told that the Primary Investigator's were studying a race related comment that was made on a university campus and we wanted their input on the situation. The individuals who participated in this investigation were informed that a university professor communicated the following remark in class:

A recent incident occurred on campus and a research team was asked to investigate reactions to the occurrence. The event occurred in a course similar to the one that you are currently taking. The professor was handing back final exam grades for the course. The (race of professor) professor said, "Of course the final exam grades were lower than usual because we have a lot of (race of the students) students in this class."

The participants were randomly assigned to one of four conditions. The professor was Black or White and the students to which they were referring to in their comments were either Black or White. The participants responded to the items after reading this information and they were then debriefed.

Dependent variable. The participants responded to an item about joking utilizing a 7point scales ( $1=$ Strongly Disagree to $7=$ Strongly Agree). The item was, "It was obvious that the professor was only joking."

Manipulation. The participants were randomly assigned either to one of the following conditions: (1) The professor was White and the students were White $(N=30)$; (2) The professor was Black and the students were Black $(\mathrm{N}=30)$; (3) The professor was White and the students were Black $(\mathrm{N}=26)$; (4) The professor was Black and the students were White $(\mathrm{N}=27)$.

\section{Manipulation Checks}

The participants who were randomly assigned to a condition with a White professor indicated how much they agreed with the statement, "The professor who made the comment was White." We ran a t-test, which provided evidence that the manipulation was a success, $t(111)=-8.41, p \leq .05$. Participants in the condition where the professor was White were more likely to agree that the statement that the professor was White ( $M$ $=5.20)$ than those in the condition where the professor was Black $(M=2.77)$.

Participants assigned to a condition with a Black professor indicated how much they agreed with the statement, "The professor who made the comment was Black." We ran a t-test, which provided evidence that the manipulation was a success, $t(110)=10.75, \mathrm{p}$ $\leq .05$. Those in the condition where the professor was Black were more likely to agree with the statement $(M=5.27)$ than those in the condition where the professor was White $(\mathrm{M}=2.54)$. 


\section{Quantitative Results}

\section{Hypothesis Testing}

The correlations and descriptive statistics are presented in Table 1. In addition, we used hierarchical multiple regression to test our hypotheses, and the data was split on the student manipulation.

Table 1

Means, Standard Deviations, and Correlations among Variables

\begin{tabular}{lcccccccc}
\hline Variable & Mean & SD & 1 & 2 & 3 & 4 & 5 & 6 \\
1 Modern Racism & 3.55 & 1.20 & - & & & & & \\
2 Race ${ }^{\mathrm{a}}$ & .62 & .49 & $.48^{* *}$ & - & & & & \\
3 Racial Identification & 3.77 & 1.42 & $.30^{* *}$ & .02 & - & & & \\
4 Gender Identification & 4.73 & 1.08 & .12 & .06 & $.26^{* *}$ & - & & \\
5 Professor & .50 & .50 & .14 & .12 & .08 & .06 & - & \\
6 Social Dominance Orientation & 3.13 & .90 & $.49^{\star *}$ & $.33^{* *}$ & $.21^{*}$ & .00 & .14 & - \\
7 Perceived Joking & 2.96 & 1.59 & $.28^{* *}$ & -.02 & .07 & -.11 & .10 & $.33^{* *}$
\end{tabular}

Note. $\mathrm{N}=111-113$

${ }^{* *} \mathrm{p} \leq .01$

${ }^{*} \underline{p} \leq .05$

${ }^{a}$ Race was coded such that $0=$ Non-White and $1=$ White

${ }^{\mathrm{b}}$ Professor was coded such that $0=$ African American Students and $1=$ Caucasian Students

As mentioned, we used hierarchical multiple regression for the analysis when the students were Caucasian (see Table 3). The level of perceived joking was regressed on the control variables. This step was not statistically significant $\left(\mathrm{R}^{2}=.07\right)$. In the next step, we included the main effects of SDO and the professor. This step was significant $\left(R^{2}=.20 ; \Delta R^{2}=.12\right)$. We then included a step, which included the interaction between SDO and professor, and this step was significant $\left(R^{2}=.29 ; \Delta R^{2}=.10\right)$. Thus, individuals who are high in SDO perceived that the White professor was joking when a biased race related comment was made about White students $(\beta=.54, p \leq .05)$. These findings support Hypothesis 1 (see Figure 1).

In addition, another regression determined results when the students were African American (see Table 2). The level of perceived joking was regressed on the control variables. This step was found to be statistically significant $\left(R^{2}=.30\right)$. The following step included SDO and the professor. This step was not statistically significant $\left(R^{2}=\right.$ .36; $\Delta R^{2}=.05$ ). We then included a step, which included the interaction between SDO and professor, and this step was not significant $\left(R^{2}=.37 ; \Delta R^{2}=.01\right)$. Thus, there was 
no significant interaction in terms of perceived joking when the students were Black. These findings do not support Hypothesis 2.

Table 2

\begin{tabular}{|c|c|c|c|c|}
\hline Step & Variable & $\beta$ & $\mathrm{R}^{2}$ & $\Delta \mathrm{R}^{2}$ \\
\hline 1 & $\begin{array}{l}\text { Modern Racism } \\
\text { Race } \\
\text { Racial Identification } \\
\text { Gender Identification }\end{array}$ & $\begin{array}{l}.67^{*} \\
-.26 \\
-.16 \\
-.10\end{array}$ & $.30^{*}$ & \\
\hline 2 & $\begin{array}{l}\text { Modern Racism } \\
\text { Race } \\
\text { Racial Identification } \\
\text { Gender Identification } \\
\text { SDO } \\
\text { Professor }\end{array}$ & $\begin{array}{l}.56^{\star} \\
-.31^{\star} \\
-.19 \\
-.04 \\
.27^{\star} \\
.00\end{array}$ & .36 & .05 \\
\hline
\end{tabular}

3

Modern Racism

Race

Racial Identification

Gender Identification

SDO

Professor

SDO * Professor
$.57^{*}$

$-.32^{*}$

$-.22$

$-.03$

$.39 *$

$-.01$

$-.16$

Note. $N=56$

* $p \leq .05$

${ }^{\text {a }}$ Race was coded such that $0=$ Non-White and $1=$ White

${ }^{\mathrm{b}}$ Students was coded such that $0=$ African American Students and $1=$ Caucasian Students 
Figure 1. Interaction of social dominance orientation and the race of the professor on the perception of joking - White Students

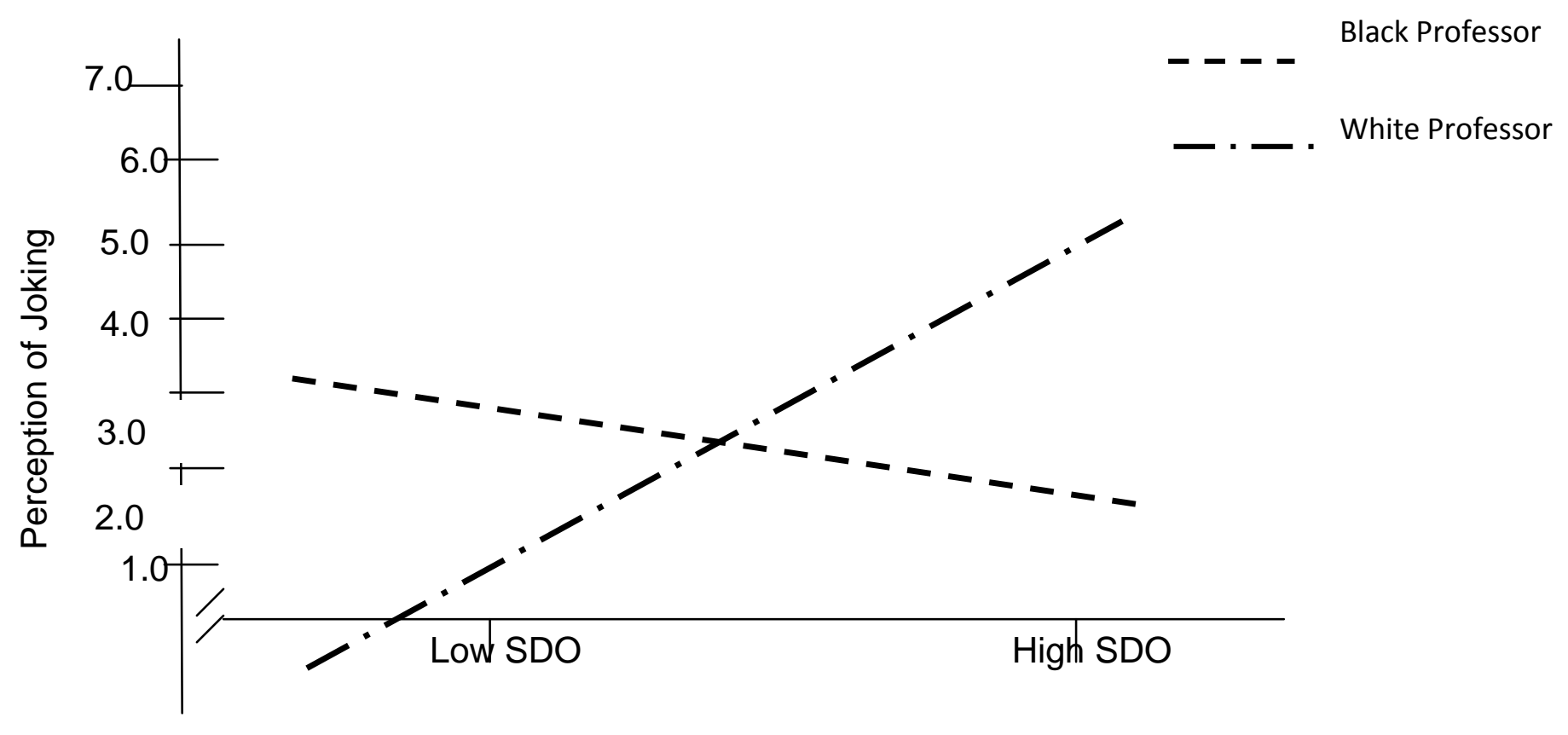


Table 3

Caucasian Students Results of Regression

\begin{tabular}{lllll}
\hline Step & \multicolumn{1}{c}{ Variable } & $\beta$ & $\mathrm{R}^{2}$ & $\Delta \mathrm{R}^{2}$ \\
\hline 1 & Modern Racism & .04 & .07 & \\
& Race & -.11 & & \\
Racial Identification & .15 & & \\
Gender Identification & -.25 & & \\
& & & & \\
& Modern Racism & -.12 & $.20^{*}$ & $.12^{*}$ \\
& Race & -.17 & & \\
Racial Identification & .14 & & \\
Gender Identification & $-.29^{*}$ & & \\
SDO & $.32^{*}$ & & \\
Professor & .18 & & \\
& & & & \\
& & & & \\
& Modern Racism & -.06 & $.29^{*}$ & \\
Racial Identification & -.13 & & \\
Race & .22 & & \\
Gender Identification & $-.31^{*}$ & & \\
SDO & -.17 & & \\
Professor & .21 & & \\
SDO * Professor & $.54^{*}$ & & \\
& & &
\end{tabular}

Note. $N=56-57$

* $p \leq .05$

${ }^{\text {a }}$ Race was coded such that $0=$ Non-White and $1=$ White

${ }^{\mathrm{b}}$ Students was coded such that $0=$ African American Students and $1=$ Caucasian Students

\section{Qualitative Methods}

The participants also shared their thoughts regarding the condition in which they participated. This open-ended question at the end of the surveys stated, "Please share your thoughts about the comment made by the professor." The purpose was to understand the reasons for the respondents' answers to the survey, and to give them the opportunity to share any additional thoughts that were not specifically addressed in the survey. 
The analytical goal of the qualitative data was to determine patterns in the participants' responses, as well as notable variations in their perspectives to provide a nuanced understanding of the quantitative results. Thus, we focused on high SDO's beliefs that the professor's comments reflected joking and/or racism in the context of the four conditions. The patterns were identified by way of entering the text into Atlas ti., a qualitative analysis program, and coding the interview responses based on a category that was defined prior to analyzing the comments to ensure that the phenomena revealed in the data were appropriately identified. This process was also followed to ensure consistency in the coding.

\section{Qualitative Results}

Ninety-two subjects completed the qualitative portion the questionnaire. Twenty-four percent of respondents in Condition 1 (Caucasian professor-Caucasian students) perceived that the professor was joking, though some also commented about the appropriateness of the "joke." All of the high SDO respondents thought it was a joke, as did some low SDO subjects. The subjects' remarks included:

"I think he was joking. I guess it was offensive to white students."

"Even though not politically correct, it could be a joke."

"I don't view it as a racist comment. I think he was making a stereotypical joke to be taken lightly."

"It was probably said in a joking manner. I feel that people who take this the wrong way are way out of touch."

However, a lesser proportion of students (17\%) thought it was a joke when the professor was Black and the students were White (Condition 4). Far more students believed that the professor's comments were racist and/or racially stereotypical and were inappropriate. Several suggested that the professor should be formally disciplined for making the comment. These individuals also included all of high SDO respondents and some low SDO subjects. Students' remarks were as follows:

"The comment was definitely unnecessary. Any stereotype or racism should be left out of the classroom."

"What he said was racist and out of line and he should face punishment."

"Prime example of how racism is alive and well."

Thus, joking was primarily perceived among students when the professor and students were both White, as opposed to when the professor was Black and the students were White. This perception was expressed by all of the high SDO subjects. The finding supports Hypothesis 1, such that high SDO's were more likely to believe that the professor was joking when White students were the target of derogatory race related comments and a White professor was the source. Yet, they were less likely to perceive joking and, in fact, more likely to perceive racism when the professor was Black and the students were White.

An interesting finding is that irrespective of SDO, no one in the study indicated that the professor's comments regarding the lower test scores of Caucasian students 
(Conditions 1 and 4) were at all accurate. Indeed, the highest proportion of respondents who thought the professor was joking was in Conditions 1 and 4 . This is particularly striking, given that a few students, all of whom were high SDO, expressed belief in the statements about the African American students' lower test scores (Conditions 2 and 3). It appears that the subjects who were high in SDO were more likely than all other respondents to believe that African Americans were, indeed, prone to poor academic performance and, notably, did not perceive the professor's comments to be jokes (irrespective of the professor's race). However, none of the subjects in Conditions 1 and 4 expressed any belief that White students performed poorly on the test, including the respondents who were not White.

\section{Discussion}

This paper examines the impact of SDO on students' beliefs that a professor was joking when a race-related comment was made. We argue that individuals who are high in SDO are more likely to perceive joking when the comments were made by a White professor who is of the same race as the target of the comments, but will not perceive joking when the comments were made by a Black professor about White students. Our quantitative analysis demonstrated that when a White professor made a biased comment about White students, individuals high in SDO perceived joking; however, this was not the case when the professor was Black. In addition, we discovered that when the students were Black, there was no significant difference of perceptions of joking from those high in SDO when the comments originated from a Black or White professor. More specifically, individuals who were high in SDO did not believe that the professor (Black or White) was joking when derogatory comments were made about Black students, but they indicated that these statements were accurate.

It is apparent that individuals who are high in SDO thought the White professor was joking when a race related remark was made about White students. In essence, they did not tend to perceive racism, and may have thought the professor had the right to make racial comments about white students. High SDO's do not agree when a high status group member makes a devaluing remark about other high status group members, joking or not; however, high SDO's desire to yield to and respect authority allows them to overlook this type of comment from a White professor (i.e., a high status group member). However, this was not the case when a Black professor made the identical comments. When a Black professor made a comment about White students, high SDO's didn't perceive a joke, but where offended. The qualitative data supported the idea that high SDO's perceived racism when it was a Black professor and White student, and we ran additional quantitative analysis to examine the idea that those participants perceived racism. A t-test was run on the item, "The comment made by the professor was racist." it indicated that that participants believed that the Black professor was racist in this circumstance while this as not the case for the White professor, $t(54)=$ $2.13, p \leq .05$.

Both the quantitative and qualitative data indicate that the benefit of the doubt was given to the White professor when comments were made about White students, in which high 
SDO's assumed that the high status group member (i.e., the White professor) must be joking when a biased race related comment was made, while this was not the case for a Black professor. High SDO's are intent on ensuring that long standing hierarchies within society stay in place and they appear to have a negative response when Blacks make comments or display behaviors that do not align with their beliefs and appear to be hierarchy attenuating.

\section{$\underline{\text { Practical Implications }}$}

Studies have found that Whites are favored over all other ethnicities, even when evaluated by different racial groups. They are considered to be a high status social group and, therefore, represent the subconscious prototype of competence in some professions (DiTomaso et al. 2007; Rosette, Phillips, \& Leonardelli, 2006). As suggested by this study, the beliefs about Whites' archetype of competence can, apparently, extend to perceptions of academic performance.

These findings are valuable as evaluations of competence in the workplace obviously extend to performance assessments and work-related rewards, such as promotions, salary increases, specialized training opportunities and access to important projects. More specifically, individuals who are considered competent, and thereby better performers, tend to be compensated and rewarded for the value they bring to the organization (Wright \& Boswell, 2002). Thus, if even undergraduate students believe that Whites represent a norm of capability over other racial groups, this may extend to their assessments of managers, colleagues and subordinates when they enter the workplace. In order to combat biases that can hinder promotions or pay increases or other work rewards these decisions should be transparent, such that managers and human resources should document justifications for business decisions. These decisions should be reviewed in aggregate periodically to determine if biases are prevalent in workplace reward decisions (Parks-Yancy 2010).

\section{Limitations and Future Research}

As with the majority of investigations, this study has limitations. For example, the generalizations of these findings are limited in that we captured the responses about an encounter that was only between Blacks and Whites. These findings would be enhanced if this investigation was conducted in which comments from multiple sources, in terms of race, were captured. Perhaps perceptions would be different if a Hispanic or Native American (low status group members) made a race related comment about a White individual and vice versa. However, we do believe that it was appropriate that the initial investigation focused on Blacks and White when one considers the unflattering historical relationship between these two races (Parks-Yancy, 2010). It is also a limitation that this study was conducted utilizing undergraduate students, and it may be appropriate to take into account the age and education level of participants in future work to determine the influence of these constructs on outcome variables. Although the generalizability of our study is limited, it is important to investigate these relationships in a controlled setting as we were able to isolate our key constructs and more specifically 
evaluate vital relationships (Kerlinger \& Lee, 2000). However, it would be important to replicate these findings in an organizational setting.

\section{Conclusion}

Unlike many survey studies, this paper provides both quantitative and qualitative data. This is important for capturing a more complete understanding of the hypotheses results by way of obtaining the respondents' perceptions, too. Thus, this paper addressed not only the hypotheses findings, but also provided some insight about the reasons behind the results. We found that Whites were perceived to be joking when a derogatory race related comment was made about Whites, but that when Blacks make the same comment about Whites it was perceived as racism. In addition, the qualitative results suggest that Whites are given greater benefit of the doubt regarding alleged poor academic performance, while Blacks are not. More specifically, we found that when a derogatory race related remark (from a Black or White authority figure) is made about Blacks it is not considered to be a joke, but the truth.

\section{References}

Cunningham, G. B., Ferreira, M. \& Fink, J. S. (2009). Reactions to prejudicial statements: The influence of statement content and characteristics of the commenter. Group Dynamics: Theory, Research, and Practice, 13, 59-73.

Davidson, C. (1987). Ethnic jokes: An introduction to race and nationality. Teaching Sociology, 15, 296-302.

Davidson, M., \& Friedman, R. (1998). When excuses don't work: The persistent injustice effect among Black managers. Administrative Science Quarterly, 43, 154-183.

Davies, C. E. (2010). Joking as boundary negotiation among 'good old boys': 'White trash' as a social category at the bottom of the Southern working class in Alabama. Humor, 23, 179-200.

DiTomaso, N., Post, C., Smith, D. R., Farris, G. F., and Cordero, R. (2007). Effects of structural position on allocation and evaluation decisions for scientists and engineers in industrial R\&D, Administrative Science Quarterly, 52, $175-207$.

Duncan, J. W. (1982). Humor in Management: Prospects for Administrative Practice and Research. Academy of Management Review, 7, 136 - 142.

Edmondson, V. C., Barnes, J., Gupte, G. (2008). Weakness in numbers: Towards an understanding in employees of color's responses to organizational research efforts. Institute of Behavioral and Applied Management, 10, 89 - 109.

Essed, P. (1990). Everyday Racism: Reports from Women of Two Cultures, Alameda, CA: Hunter House

Hughes, M. K. (2003). Through the looking glass: Racial jokes, social context and the reasonable person in hostile work environment analysis. Southern California Law Review, 76, 1437-1482.

Kerlinger, F. N., \& Lee, H. B. (2000). Foundations of behavioral research $\left(4^{\text {th }}\right.$ 
Ed.). Fort Worth, TX: Holt, Rinehart, and Winston.

McClelland, K. E. \& Auster, C. J. (1990). Public platitudes and hidden tensions racial climates at predominantly white liberal arts colleges. Journal of Higher Education, 61, 606 - 642.

McConahay, J. B., Hardee, B. B., \& Batts, V. (1981). Has racism declined in America? It depends on who is asking and what is asked. Journal of Conflict Resolution, 25, 563-579.

Morrison, K.R. \& Ybarra, O. (2008). The effects of realistic threat and group identification on social dominance orientation. Journal of Experimental Social Psychology, 44, 156-163.

Park, J. H., Gabbadon, N.G. \& Chernin, A. R. (2006). Naturalizing racial differences through comedy: Asian, black, and whites views on racial stereotypes in Rush Hour 2. Journal of Communication, 56, 157-177.

Parks-Yancy, R. (2010). Equal work, unequal careers: African-Americans in the workforce. Boulder, CO: First Forum Press.

Pratto, F., Stallworth, L. M., Sidanius, J., \& Siers, B. (1997). The gender gap in occupational role attainment: A social dominance approach. Journal of Personality and Social Psychology, 72, 37-53.

Rosette, A. S., Leonardelli, G. J., \& Phillips, K. W. (2008). The white standard: Racial bias in leader categorization. Journal of Applied Psychology, 93, 758-777.

Sidanius, J., \& Pratto, F. (1999). Social dominance: An intergroup theory of social hierarchy and oppression. Cambridge: Cambridge University Press.

Sidanius, J., Pratto, F., Sinclair, S. \& van Laar, C. (1996). Mother Teresa Meets Genghis Khan: The Dialectics of Hierarchy-enhancing and Hierarchy attenuating Career Choices. Social Justice Research, 9,145-170.

Sidanius, J., \& Veniegas, R. C. (2000). Gender and race discrimination: The interactive nature of disadvantage. In S. Oskamp (Ed.), Reducing prejudice and discrimination: The Claremont symposium on applied social psychology (pp. 47-69). Mahwah, NJ: Erlbaum.

Sidanius, J., \& Pratto, F. (2003). Social dominance theory and the dynamics of inequality: A Reply to Schmitt, Branscombe, \& Kappen and Wilson \& Liu. British Journal of Social Psychology, 42, 207-213.

Sidanius, J., Pratto, F., van Laar, \& Levin, S. (2004). Social dominance theory: Its agenda and method. Political Psychology, 25, $845-880$.

Simmons, A. L. \& Parks-Yancy, R. (2011, August). A quantitative and qualitative analysis of social dominance orientation and race-related comments. Presented at the annual meeting of the Academy of Management, San Antonio, Texas.

Umphress, E. E., Simmons, A. L., Boswell, W. R. \& Triana, M. (2008). Managing discrimination in selection: The influence of directives from an authority and social dominance orientation. Journal of Applied Psychology, 93(5), 982993.

Wright, P. M. \& Boswell, W. R. (2002). Desegregating HRM: A review and synthesis of micro and macro human resource management research. Journal of Management, 28, 247-276. 